\title{
Memórias inscritas nas imagens ${ }^{1}$
}

\author{
Mayra Rodrigues Gomes²
}

1 A propósito deste título, que talvez insinue outro sentido, gostaria de frisar que é da natureza da memória o estar encravada nas imagens.

2 Professora Titular do Departamento de Jornalismo e Editoração da Escola de Comunicações e Artes, Universidade de São Paulo. mayragomes@usp.br. 


\section{Resumo}

Escrito a título de homenagem, o presente artigo se inscreve, apropriadamente, como memória, a partir dos dois registros com que a preservamos: o do contato pessoal e o do contato intelectual que se tece, frequentemente, das fibras de ideias, conhecimentos e panoramas compartilhados. Presentemente, faço uma mixagem entre a vivência, a produção textual do passado e aquilo que hoje experimento como tendo sido refletida nela. Memória é isso, sempre uma fusão, como a que acaba de surgir na montagem deste texto.

Palavras-chave

Memória, Eduardo Peñuela Cañizal, imagens.

\section{Abstract}

A tribute to professor Eduardo Peñuela Cañizal, the present article is given as a memoire in two senses: the personal connection and the intellectual exchange allowed by the fabric of shared knowledge, ideas and perspectives. So what I present here is a mixture between my past textual production and experiences and what I now realize it reflects. Memory is always about a fusion, just as the one happening for the structuring of the present text.

\section{Keywords}

Memory, Eduardo Peñuela Cañizal, images. 
Recupero, neste artigo, a dedicatória com que introduzi Bordando o manto do mundo: o surrealismo e o nome das coisas, texto publicado tempos atrás na revista Significação, revista mantida, estimulada e levada a diante, por muitos anos, pelo professor Eduardo Peñuela Cañizal.

Ao Professor Eduardo Peñuela Cañizal.

O brilho de suas aulas em débito ao de sua pessoa.

Pequeno texto, dedicado a um grande mestre.

Escrito a título de homenagem, o presente artigo se inscreve, apropriadamente, como memória, a partir dos dois registros com que a preservamos: o do contato pessoal e o do contato intelectual que se tece, frequentemente, das fibras de ideias, conhecimentos e panoramas compartilhados.

Às vezes conhecemos uma pessoa muito antes de encontrá-la pessoalmente, por suas obras e seus efeitos. Foi assim que soube do professor Eduardo Peñuela Cañizal, pouco mais de uma década antes de vir a ser sua aluna na Escola de Comunicações e Artes da USP (ECA-USP).

A professora Dulcília Buitoni era uma colega e, mais tarde, minha orientadora na pós-graduação, quando ainda era estudante do Departamento de Jornalismo e, eu, estudante do Departamento de Filosofia, ambos da USP. Ela um dia me contou que estava cursando disciplina muito instigante, ministrada por excelente professor, especialista em semiótica. Disse que uma das indicações de leitura para a disciplina era o livro A morte de Artemio Cruz, de Carlos Fuentes, e o livro era tão "bárbaro" quanto disciplina e professor.

Estávamos no bojo da virada dos anos 70, quando a questão de novas experiências e experimentos era pauta máxima, onipresente. Carlos Fuentes, que fui ler avidamente, experimentou, no livro mencionado, com um novo esquema do jogo que se articula entre enunciador e enunciado. Tal jogo comporta a inserção do sujeito no discurso, o questionamento desse sujeito como sujeito da enunciação ou como sujeito que possa ser alguma outra coisa fora dela. Pois, a brincadeira/exercício a que se entrega Carlos Fuentes em seu livro, com a 
inversão das pessoas do discurso, abre justamente para essa brecha, onde mais tarde Michel Foucault viria a questionar, afinal, o que é um autor.

Retive na lembrança o livro, não retive o nome daquele que o indicara, mas retive as descrições elogiosas da Dulcília sobre professor, sobre conteúdo da disciplina e sobre o encantamento que dela emanava.

Em 1985, depois de muitas voltas e reviravoltas da vida, retornei à USP para fazer pós-graduação e, sob aconselhamento da orientadora, lá fui eu cursar disciplina do professor que indicara a leitura de Carlos Fuentes. Era o Professor Eduardo Peñuela Cañizal, já uma lenda na escola, a falar sobre o quadrado semiótico de Greimas, sobre figuras de linguagem que exemplificava com imagens de filmes e de pinturas. Este foi o caso da inesquecível exploração do quiasma, e, naturalmente, sobre o surrealismo, sua paixão.

Como se sabe, o movimento é, até certo ponto, equacionado pelas propostas de André Breton em Manifestos do surrealismo. Há duas enunciações das propostas, uma em 1924, outra em 1930. Em 1924, há ênfase no trabalho do inconsciente e uma espécie de casamento com conceitos psicanalíticos. Em 1930, dá-se prioridade à diluição de fronteiras entre relações opositivas, entre o que mais tarde, numa perspectiva lacaniana, será chamado de real, simbólico e imaginário.

Os dois focos eram visitados pelo professor, a tal ponto que, falar em surrealismo, era, na Escola de Comunicações e Artes, falar de Peñuela, abreviação pela qual todos o conheciam. Na esteira do surrealismo, navegávamos pelas obras de Pablo Picasso (sem esquecer a controvérsia sobre sua classificação como surrealista), Salvador Dalí, Luis Buñuel e tanto outros, como Jean-Luc Godard, afinados com o surrealismo em virtude de inovações, de inversões de sentido, da criatividade como exercício e do desejo como instância que anima o mundo.

Aliás, das peculiaridades que se destacavam no modo de ser do professor, uma era a ênfase dada à palavra desejo, que era pronunciada de boca cheia, em forma escandida, acompanhada de levantar de sobrancelhas e olhar maroto. 
Outras a serem lembradas eram as baforadas do cachimbo que se confundia, afinal, com as análises do quadro Ceci n'est pas une pipe, de Renée Magritte.

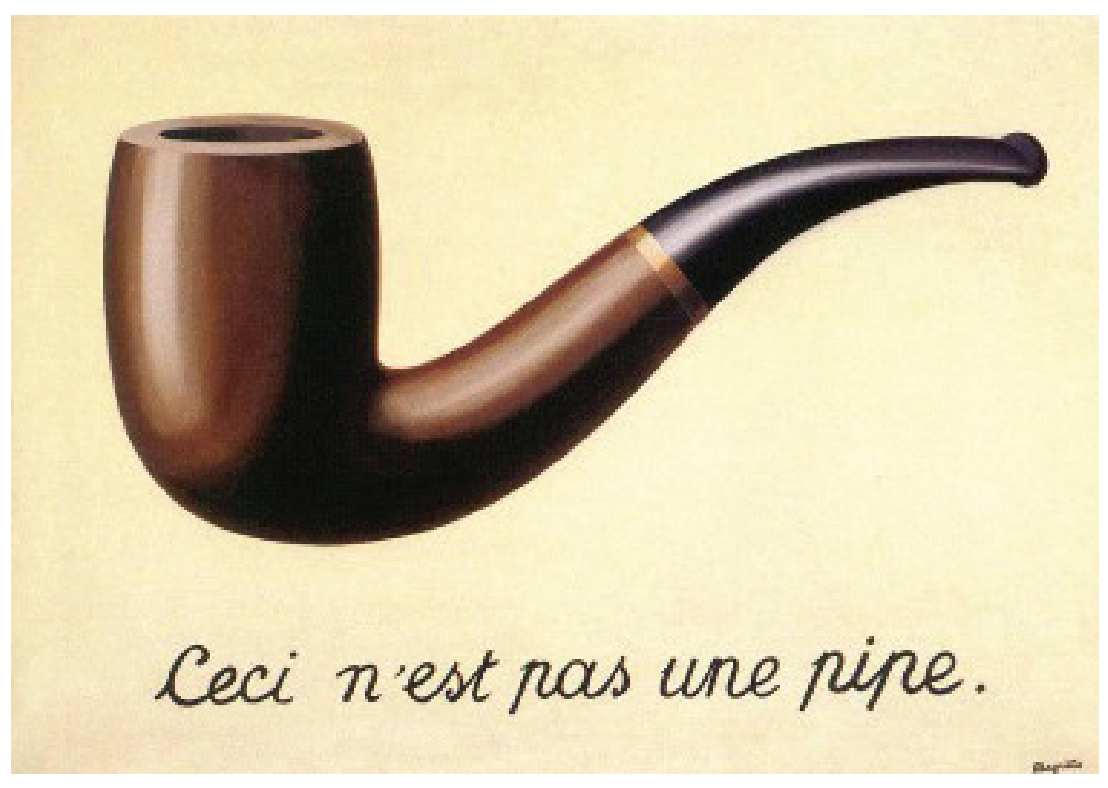

Figura 1: Ceci n'est pas une pipe, 1928/1929

Sim, Magritte, um de meus preferidos, estava lá, sua obra como exemplo e lugar de exploração para as figuras de linguagem, tanto quanto para ideias caras ao surrealismo: a subversão de sentido, ou melhor, o apontamento de um sentido oculto que alude, sempre, a uma realidade outra.

Vejamos, a título de exemplo de exploração, como a famosa pintura Le blanc-seing, 1965, uma das obras analisadas pelo professor, presta-se a esse tipo de exercício. A rigor, no registro do trompe l'oeil, o quadro se compõe com os planos que se conjugam para formar um todo. Mas, atenção, essa é uma das grandes questões do surrealismo, a composição desse todo é trabalho de nosso olhar e mente, segundo realidades que nos são familiares. Tanto é assim que o título tem como significado mais próximo tudo que conhecemos como "carta branca". Há uma pré-autorização no quadro em diversos níveis, todos eles de ordem da nossa cultura e, certamente, um de ordem universal: o nível cognitivo. 


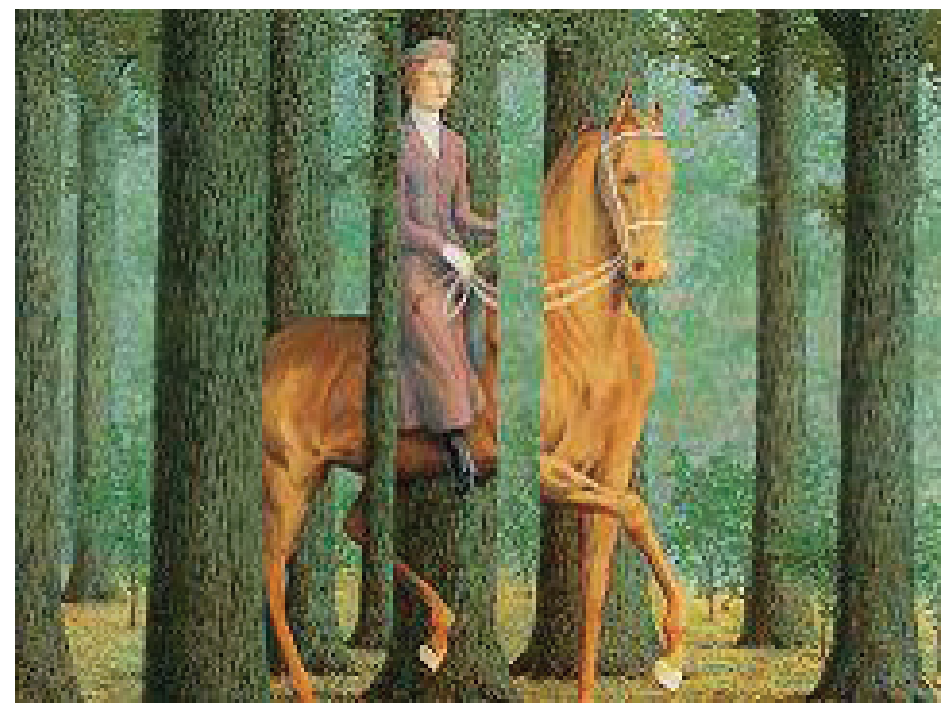

Figura 2: Le blanc-seing, 1965

Alguns anos depois, quando eu fazia o doutorado, tornei a assistir esse curso, agora em companhia de várias colegas, como a Beltrina Corte, a Rosana Soares e a Rose Rocha, para cujas presenças eu própria havia contribuído, fazendo propaganda do lucro e da satisfação que se obtinham com as aulas do Peñuela.

Por essa época, eu estava absolutamente mergulhada na leitura de Jacques Lacan, pensando sua obra em relação à linguagem, tentando entender a extensão de seu estatuto na construção de subjetividade.

Tal leitura nunca deixa de estar acompanhada, entre outras, pela leitura de obras voltadas para as teorias da representação. Pois, no limite da redução, Lacan nos fala sobre uma impossibilidade basal de representar a "coisa", ficando nós confinados a representar, simplesmente, a representação.

Ora, não que a obra de Magritte se dedicasse somente a explorar essa condição, fato que seria de incrível excepcionalidade, mas, boa parte dela esta nisso empenhada ao ponto de constituir, ela própria, uma teoria da representação.

Naturalmente, tudo começa, de forma explícita, com o trabalho intitulado Trahison des images (1929) em que, sob a pintura de um cachimbo, estão escritas/desenhadas as palavras Ceci n'est pas une pipe. Outras obras de 
Magritte estão sob a rubrica de traição das imagens. Todas elas desdizem a presença real do objeto representado pela pintura. Escrevi, alguns anos depois, sobre as circunstâncias do quadro e a propósito do estatuto da representação:

Traição das imagens e traição das palavras, enquanto pensadas como correlatos a seus referentes. A alusão à constituição dos signos, imagéticos ou verbais, fez desse quadro uma citação corrente em tratados de semiótica. Nesse caso, ele serve de demonstração para uma condição sígnica básica, a saber, a distância (ou diferença) intransponível entre representação e representado, entre signo e referente.

Neste quadro, a obra de arte é desviada do estatuto representação/ semelhança. Como tal estatuto se firma sobre a relação entre referente e signo, esta é deslocada do vetor realismo, a saber, a aproximação com maior fidelidade da representação ao representado, para ser colocada como criação.

No jogo entre palavra e imagem que o quadro comporta, resume-se uma tomada teórica que nos conduz ao entendimento do universo, enquanto instância à qual temos acesso somente como inscrição, ou seja, enquanto instância organizada/produzida pela via da simbolização, como realidade construída, como, ao invés de representação, uma "apresentação do mundo" (GOMES, 2005, p. 12).

Nesse antigo artigo, que já homenageava o professor, segui alguns caminhos, fiz escolhas que determinavam uma direção de leitura. No de hoje, dou-me ao luxo de visitar outras obras e seguir um trajeto diverso daquele trilhado pelo professor, mas que em tudo se afina com a ideia central de suas aulas. Presentemente, faço uma mixagem entre a vivência, a produção textual do passado e aquilo que hoje experimento como tendo sido refletida nela. Memória é isso, sempre uma fusão, como a que acaba de surgir na montagem deste texto.

Feita essa observação, retomo ao ponto em que me encontrava. Igualmente explícito é o quadro La reproduction interdite, em que vemos as costas de um rapaz parado em frente de um espelho. No entanto, o espelho, em vez de nos mostrar seu rosto nos mostra exatamente as mesmas costas já pintadas no quadro. 


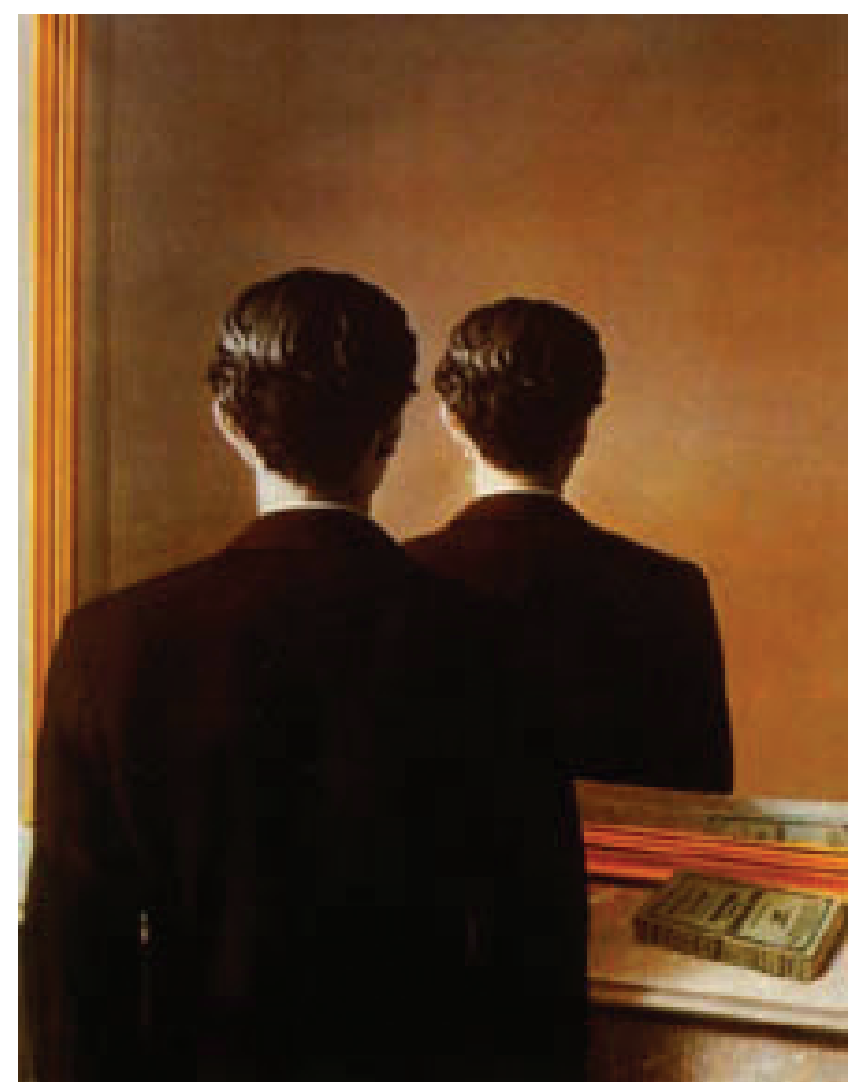

Figura 3: La reproduction interdite, 1937

Devemos observar a obra de Magritte no registro da brincadeira que ele entretinha entre o quadro e o nome que Ihe atribuía. A reprodução interdita, afinal, reproduz as costas do rapaz, enquanto pintura. Mas, o estatuto do espelho, justamente o elemento a que ligamos a forma privilegiada da representação, é subvertido, ao ponto de lembrar-nos que os espelhos são parciais e, além disso, invertem o reflexo do refletido.

Ainda a propósito da destituição dos espelhos, inscreve-se a obra Le faux miroir. O quadro tem um olho como elemento que toma toda a tela e que pouco se vê de seus contornos, mas onde se refletem o céu azul claro e os flocos de brancas nuvens, tão presentes na pintura de Magritte. 


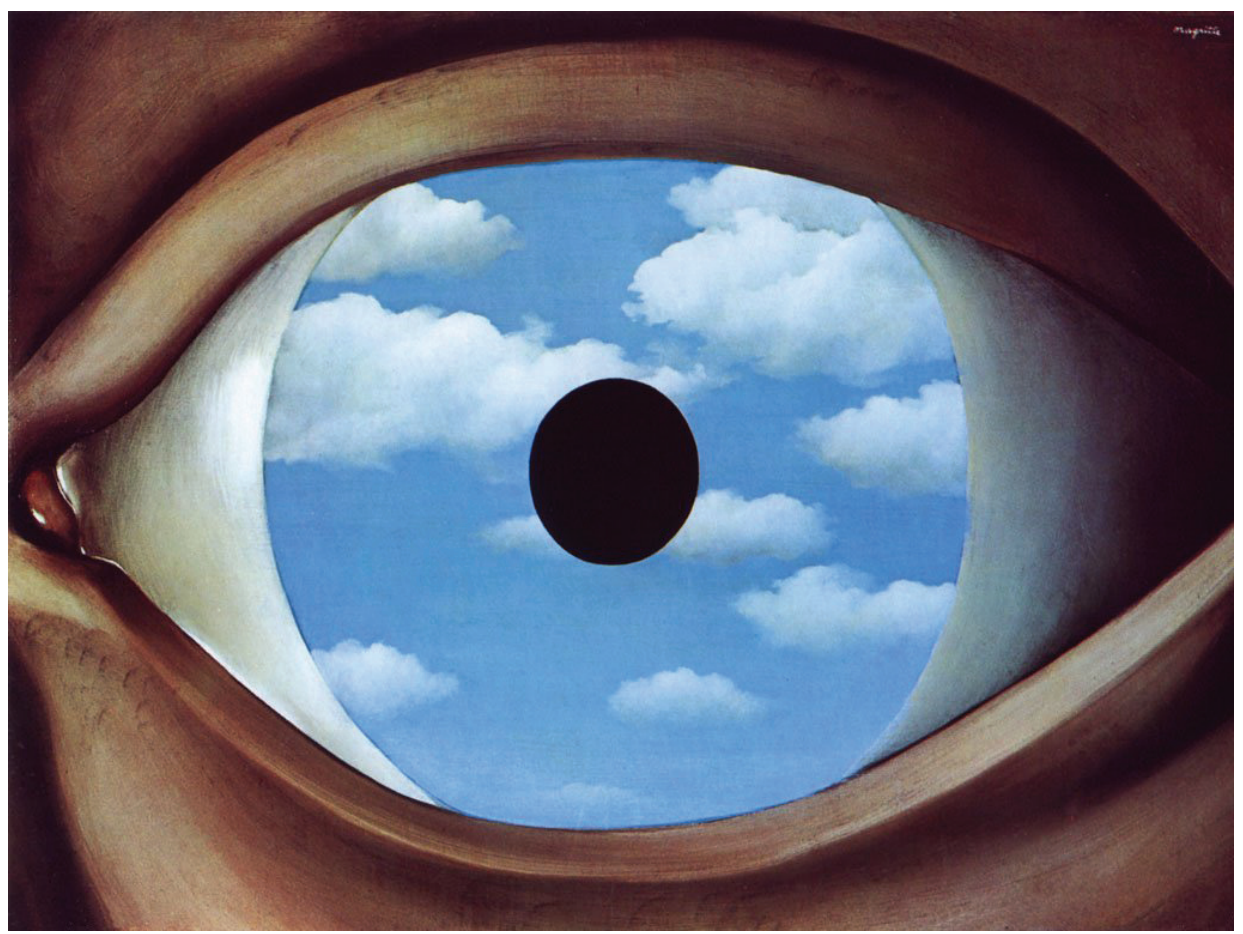

Figura 4: Le faux miroir, 1928

O falso espelho nos leva à questão psicanalítica da construção de identidade, somente realizada pela identificação, num momento inaugural em que o sujeito se vê como "inteiro" pela sua imagem refletida. Ela deve ser identificada como sua, e não pode fazê-lo sem o recurso a elementos familiares.

Basta compreender o estádio do espelho como uma identificação, no sentido pleno que a análise atribui a esse termo, ou seja, a transformação produzida no sujeito quando ele assume uma imagem cuja predestinação para esse efeito de fase é suficientemente indicada pelo uso, na teoria, do antigo termo imago (LACAN, 1998, p. 97).

Tudo isso conflui, na obra de Magritte, para suas alusões, várias, a que os espelhos não refletem o presumido, mas os dados de uma cultura. Em Le faux miroir podemos ler, dentre naturalmente muitas outras apropriações, a referência ao olhar que reflete, afinal, o que lhe é de antemão destinado a ver, ainda que o destino desemboque na maravilhosa cena azul e branca do céu. 
Uma vez mais no registro dos reflexos, que desmentem o refletido, encontramos a série de quadros sob a rubrica L'empire des lumières. Construída com claro jogo entre luz, sombras e reflexos, o conjunto, com lampiões acesos que evocam uma cena noturna, traz sempre, no entanto, um céu diurno, na conhecida elaboração que temos chamado de "o céu de Magritte".

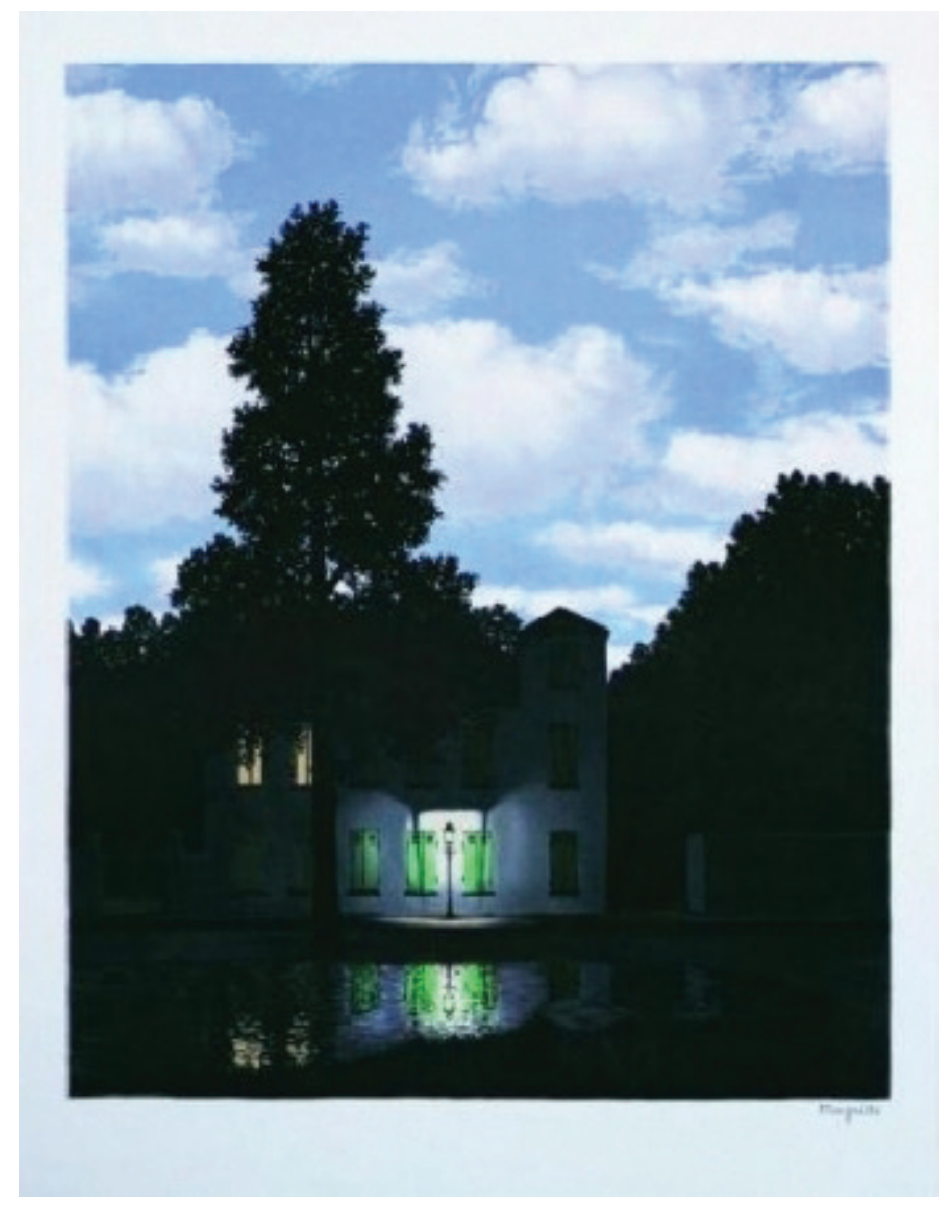

Figura 5: L'empire des lumières, 1954

Decididamente oníricos, os espelhos, os reflexos e os olhos fazem a ponte para outra das célebres preferências de Peñuela: Luis Buñuel e suas obras. Era particularmente referido em aula o filme Un chien andalou, ícone do surrealismo, obra de 1928, realizada em parceria com Salvador Dalí. Um de seus momentos de impacto, logo de início, consiste em cena do olho de uma mulher sendo cortado por uma navalha. Cena um tanto perturbadora que, no entanto, nos 
faz lembrar dessa divisão do olhar entre o seu aparato físico e o que lhe está reservado a ver.

Voltando a Magritte, devemos observar sua obra a partir de conversas com marchands e amigos, de cartas com eles trocadas, hoje em dia de fácil acesso pela internet. Nesses diálogos o pintor comenta suas intenções, ou entendimento, a cada escolha feita em uma obra. Importa anotar que seus comentários reforçam e se combinam com aqueles que apresentamos aqui.

A esse propósito, há dois de quadros sob a rubrica La condition humaine, um de 1933, outro de 1935, bastante comentados e conversados pelo pintor. 0 espírito geral dessas obras reside na apresentação de uma pintura em que há uma janela a que se antepõe um quadro em seu cavalete. Este, por sua vez, representa uma cena de fundo, que está fora da janela, hipoteticamente real e com a qual se confunde.

Se, por um lado, a pintura no cavalete encobre parte da cena na janela, supõe-se que ela também a revela, representando fidedignamente a paisagem a ser descortinada. Na segunda pintura de Magritte, o quadro no cavalete, além de se sobrepor parcialmente ao panorama da janela, estende-se para fora do batente da janela, de forma a presumir a representação em continuidade da paisagem, sem a circunscrição da moldura. 


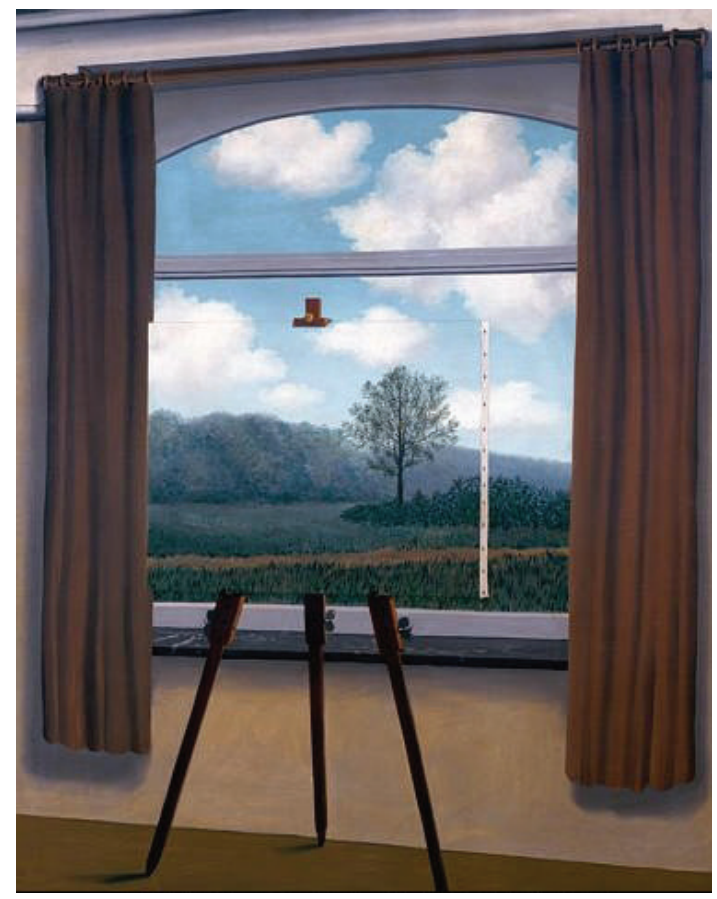

Figura 6: La condition humaine, 1933

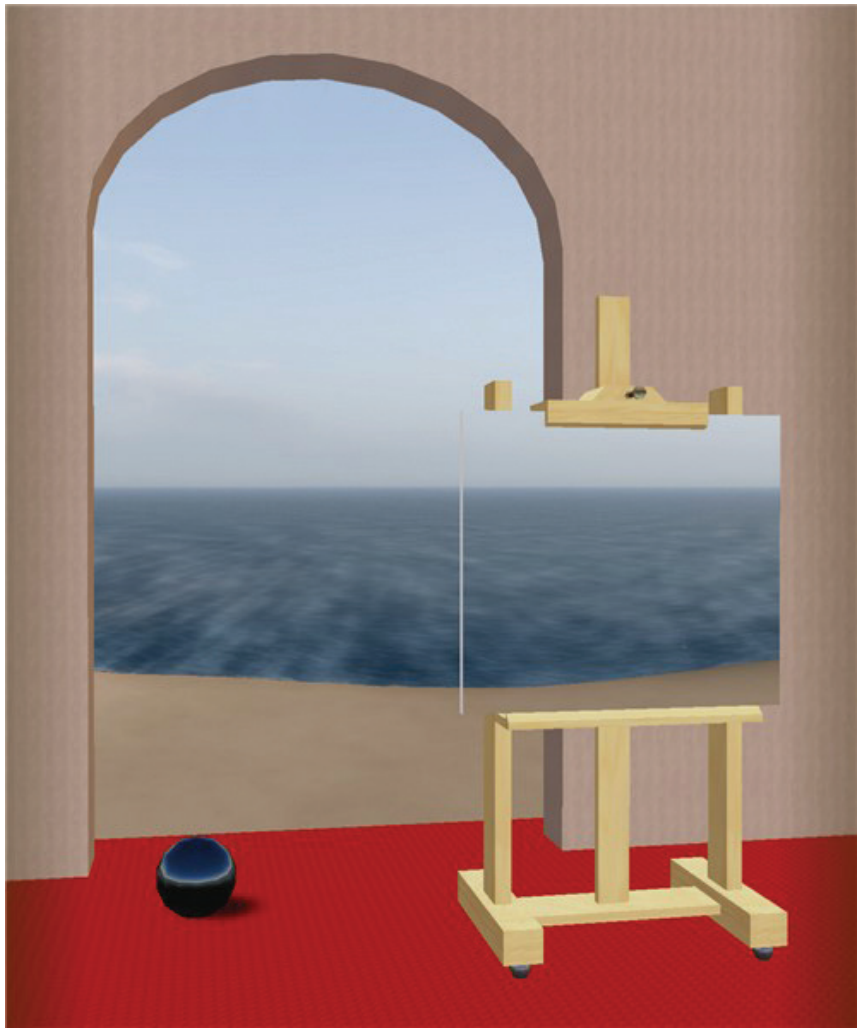

Figura 7: La condition humaine, 1935 
Claro que esses quadros são explícitos em relação a uma teoria da representação, contestando a realidade das coisas com esse olhar que as transporta para outras dimensões, naturalizando-as em estratificações que simulam reduplicar/captar, uma impossibilidade, a paisagem em sua essência.

Esse mundo, concebido como um todo, com tudo aquilo que este termo comporta, qualquer que seja a abertura que Ihe dêem, delimitado, continua sendo uma concepção - é mesmo esta palavra - uma vista, um modo de olhar, uma tomada imaginária (LACAN, 1985, p. 60).

Mas, como não poderia deixar de acontecer, e como não deixa de acontecer com as teorias da representação, o quadro comporta, também, uma teoria do sujeito. Basta olharmos o sentido que Magritte empresta a seus quadros através dos títulos escolhidos, para percebemos que esta questão está lá. Lá, na condição humana, afinal representada como circunstância de representação, com o correspondente descarte de uma identidade "única e autêntica", estão os termos que firmam o pacto da realidade. Esta é tecida entre o Real, como pressuposto lógico, e a malha trançada entre o Simbólico e o Imaginário.

Estes assuntos vinham à baila, certamente não nos termos em que os coloco agora, nas conversas após a aula. Peñuela dava aulas nas quartas-feiras e nas quartas, após a aula, professor e alunos de pós-graduação se reuniam no restaurante do, então, Clube dos Professores. Alguns ex-alunos, que o acompanhavam há anos, vinham para essa reunião às onze da noite. Petiscos e alguns drinques eram acompanhados de intensas fabulações, ao gosto dos fregueses.

Nem sempre eu podia estar presente, mas com frequência estava lá, usufruindo da oportunidade impar de estar entre amigos e de jogar "papo fora". Conversávamos sobre tudo que é do universo da arte, desde os clássicos visitados nas aulas até a última exposição de pintura, a última peça de teatro, o artista ou o filme do momento. Foi assim que fiquei conhecendo alguns cineastas de peso, foi assim que os incorporei a minhas preferências. 
O cineasta inglês Peter Greenaway foi incorporado de chofre, desde a exibição em aula de seu filme, de 1982, The draughtsman's contract. Claro que, assim como nas pinturas que eram mostradas em classe, a questão central de O contrato era a do olhar e do que é visto por um olhar sempre comprometido com algumas ideias guia, ainda que aquele que vê não tenha noção delas. Aliás, ao acompanharmos o conjunto da produção de Greenaway, podemos constatar que ela, para um lado ou para outro, sempre se cruza com este tema.

E, assim, nossas artificiosas conversas entretidas no Clube dos Professores, onde Peñuela tinha mesa cativa e era esperado pelo garçon de sempre com seu drinque favorito, fluíam em torno das imagens, das representações e, às vezes, tangenciavam epistemologias e teorias que corriam num plano de fundo, como as teorias da comunicação.

Hoje, nesta homenagem-memória com tintas do passado e pinceladas do presente, quero visitar outra obra, outro artista que não estava lá por essa época. O holandês Maurits Cornelis Escher é bastante conhecido por seus trabalhos com projeções que rompem com perspectivas tradicionais. Explorando geometrias que se contrapõem, ele cria planos sobre planos, paisagens inviáveis.

Contudo, seus exercícios, que implicam cálculos precisos, por mais improváveis que sejam na realidade da vida, alinham-se com os assuntos que escolhemos explorar aqui. 


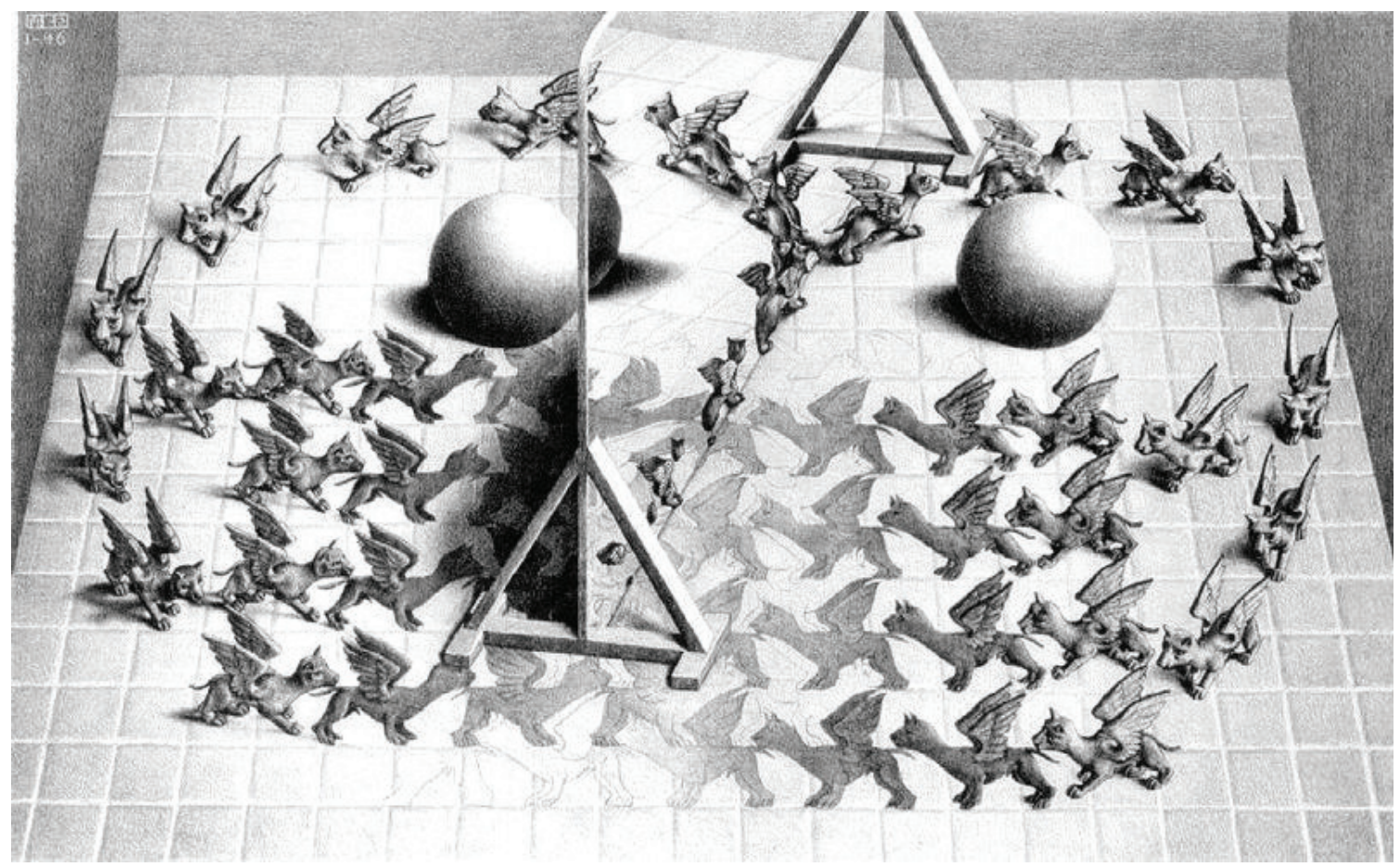

Figura 8: Magic mirror, 1946

Tomemos, para começo de nosso trajeto, sua obra intitulada Magic mirror. Tudo que é da ordem da representação e da identidade encontra-se lá. Um espelho que na realidade atravessa a cena e é só uma intersecção entre dois planos. De um lado e de outro do espelho o refletido continua como se a parte do reflexo fizesse parte do que se desenrola num continuum de materialidade a ser refletida.

O desmonte da representação enquanto réplica do representado está feito, pois o representado segue seu próprio caminho para além da representação. As identidades, a serem constatadas no espelho, mostram-se como entidades alheias a ele. Elas mantêm seu próprio deslocamento, que arrasta consigo as atribuições imaginárias. 
assim todos os disfarces imaginários dos seres e dos objetos que vêm secundariamente ocupar esses lugares" (DELEUZE, 1995, p. 276).

E os reflexos são, assim, reduzidos às circunstâncias de nossas projeções, que são projeções dos modos de ser a um tempo e lugar.

Se o que Freud descobriu e redescobre num escarpado cada vez maior, tem um sentido, é que o deslocamento do significante determina os sujeitos nos atos, no destino, nas recusas, nas cegueiras, nos sucessos e na sorte, não obstante seus dons inatos e seu crédito social, sem consideração para o caráter ou o sexo, e que, quer queira quer não, seguirá o curso do significante com armas e bagagens, tudo o que é do dado psicológico (Lacan, 1992, p.37).

Claro que reflexos e representações nos conduzem, inevitavelmente, à questão das repetições, porque é a repetição do refletido que está em jogo. E aí mergulhamos nas explorações de Deleuze que, a um só tempo, no mesmo questionamento, colocam as representações, as identidades e as repetições.

Toutes les identités ne sont que simulées, produites comme un 'effet' optique, par un jeu plus profond qui est celui de la différence et de la répétition....La tâche de la vie est de faire coexister toutes les répétitions dans un espace où se distribue la différence (DELEUZE, 1968, p .2-3).

Muitos já nos ensinaram sobre a repetição como impossibilidade, sobre o fato de que ela está destinada ao fracasso ${ }^{3}$, pois aquilo que se representa é sempre transportado a outra dimensão, a da representação, consequentemente fazendo com que o representado seja "uma outra coisa", destacada do referente. 


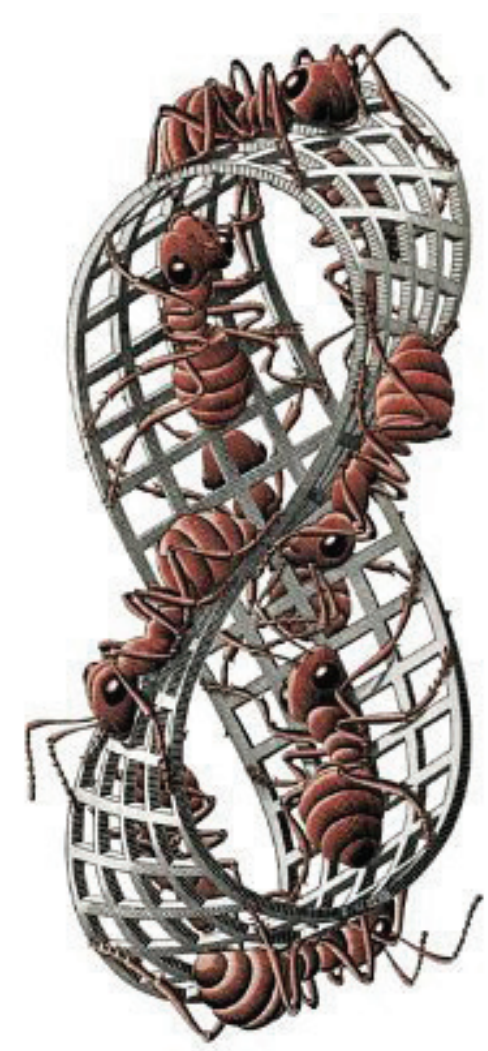

Figura 9: Mobius Strip, 1964

E se tomamos o desenho Mobius strip, de Escher, para nossas explorações é por gosto, mas também por um cadinho de coerência, pois Lacan empregou a banda de Mobius em suas explicações sobre topologia, sobre a dobra e redobra que, a um tempo, pertencem à mesma tira que, uma vez considerada a inversão das pontas unidas, a outro tempo instalam um plano diferenciado. Aliás, muito mais impactante é o fato de que não sabemos onde as pontas se unem, onde há começo e há fim.

Tudo que, na repetição, varia, modula, é apenas alienação de seu sentido. $O$ adulto, se não a criança mais desenvolvida, exige, em suas atividades, no jogo, a novidade. Mas esse deslizamento vela aquilo que é o verdadeiro segredo do lúdico, isto é, a diversidade mais radical que constitui a repetição em si mesma" (LACAN, 1995, p. 62).

Claro que está tudo dito, por Lacan, no plano do funcionamento psíquico, no plano do jogo entre significante e referente, no plano da fruição da vida. Mas 
a diferença, a diversidade, quando explicada por Deleuze, assume um estatuto cognitivo, uma imanência que se traduz em essência, na repetição.

Par le déguisement et l'ordre du symbole, la différence est comprise dans la répétition. C'est pourquoi les variantes ne viennent pas du dehors... Les variantes expriment plutôt des mécanismes différentiels qui sont de l'essence et de la genèse de ce qui se répète (DELEUZE, 1968, p.28).

A escolha como última das gravuras de Escher, Drawing hands, para este artigo se deve tanto ao seu tema, o desenho de duas mãos pintoras que se pintam a si mesmas, quanto ao trabalho do professor.

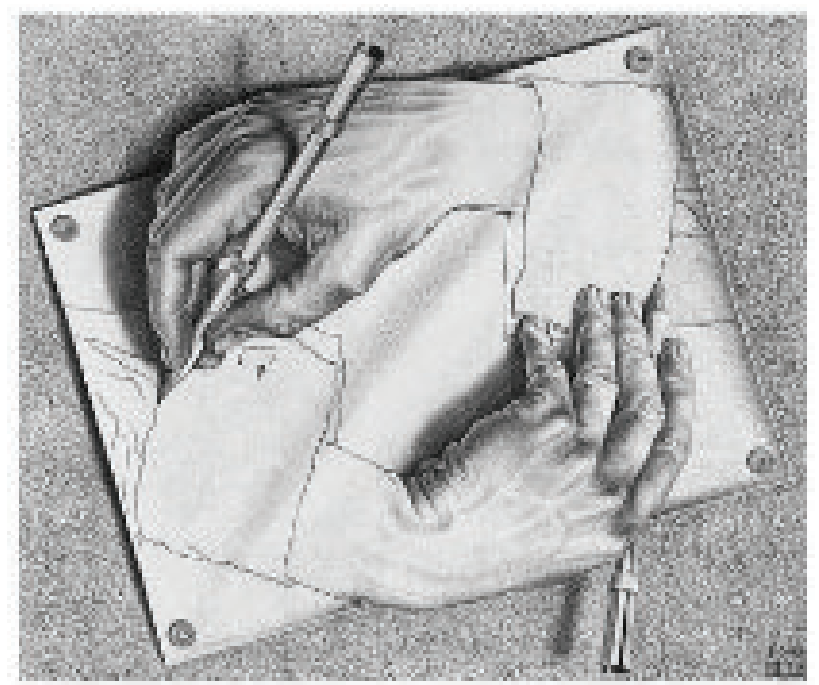

Figura 10: Drawing hands, 1948

Como representação da representação, a gravura fala, por si só, de todos os conceitos que vínhamos depurando. Fala, sobretudo, de nossos anseios, de uma arquitetura interminável de que nos alimentamos, do começo e fim que se confundem, impedindo-nos de saber tanto da junção quanto da ruptura, preservando-nos, assim, da perda, pois "Aonde está o ser, há exigência de infinitude" (LACAN, 1985, p.19).

Contudo, ela fala também das qualidades do professor que, por meio das imagens conseguia objetivar conceitos insuspeitados, muitas vezes, pelos seus 
próprios desenhistas e pintores. Nesse sentido, Peñuela era mais que artífice: era um grande mestre e, portanto, um grande artista. Para aqueles que acompanharam suas aulas e, por sua vez, também deram aulas sobre esses assuntos, cujos alunos, por sua vez... Peñuela está, merecidamente, projetado ao infinito. 


\section{Referências}

BRETON, A. Manifestos do surrealismo. Lisboa: Salamandra, 1993.

DELEUZE, G. "Como reconhecer o estruturalismo" in História da filosofia, org. François Châtelet. Lisboa, Dom Quixote, 1995.

DELEUZE, G. Différence et répétition. Paris, Presses Universitaires de France, 1968.

FOUCAULT, M. As palavras e as coisas. São Paulo, Martins Fontes, 1995.

FOUCAULT, M. Ceci n'est pas une pipe. Sur Magritte. Paris, Fata Morgana, 1973.

GOMES, M. R. "Bordando o manto do mundo: o surrealismo e o nome das coisas", publicado pela revista Significação. Revista Brasileira de Semiótica. Centro de Pesquisa em Poética da Imagem (CEPPI), ECA-USP, Universidade Tuiuti do Paraná/UTP. São Paulo, Annablume, Junho de 2005. Disponível em: http://www. revistas.usp.br/significacao/article/view/65616/68231.

KAUFMANN, P. (ed.). Dicionário enciclopédico de psicanálise. O legado de Freud e Lacan. Rio de Janeiro, Jorge Zahar Editor, 1996.

LACAN, J. Escritos. São Paulo, Editora Perspectiva, 1992.

LACAN, J. Escritos. Rio de Janeiro, Jorge Zahar, 1998.

LACAN, J. O Seminário, livro 11, Os quatro conceitos fundamentais da psicanálise. Rio de Janeiro, Jorge Zahar Editor, 1995.

LACAN, J. O Seminário, livro 20, Mais, ainda. Rio de Janeiro, Jorge Zahar, 1985.

LACAN, J. O Seminário, livro 22, R. S. I. Cópia mimeografada. Paris, 1974-1975. 